\title{
Fiscal efficiency, redistribution and welfare ${ }^{\text {放 }}$
}

\author{
Bilin Neyapti $^{\mathrm{a}, *}$, Zeynep Burcu Bulut-Cevik ${ }^{\mathrm{b}}$ \\ a Bilkent University, Ankara, Turkey \\ b METU, Ankara, Turkey
}

\section{A R T I C L E I N F O}

\section{Article history:}

Accepted 23 May 2014

Available online 19 June 2014

\section{Keywords:}

Redistribution

Fiscal efficiency

Transfer rule

\begin{abstract}
A B S T R A C T
The expanding literature on fiscal decentralization (FD) emphasizes the role of institutional mechanisms for FD's welfare effects. We analyze the welfare effects of FD in case of a fiscal transfer mechanism that punishes inefficiency in tax collection and compensates for local income deficiency. In addition, a portion of transfers is earmarked for investment. Given a level of FD and these rules, the representative local government chooses its tax collection effort to maximize local utility. The solution of the model reveals that the stricter the redistributive rule, the higher are steady-state fiscal efficiency and welfare. While the effectiveness of the redistributive parameters increases with centralization of the revenue pool, it decreases with the tax rate. Both welfare and income distribution, on the other hand, improve with the degree of revenue centralization and the tax rate. Besides, fiscal efficiency and redistribution decrease with investment-earmarked transfers.
\end{abstract}

(C) 2014 Elsevier B.V. All rights reserved.

\section{Introduction}

Fiscal decentralization (FD), defined as the devolution of fiscal power and responsibilities from the central government toward local governments, has been in practice by varying degrees in a growing number of countries. As a mechanism theorized to promote fiscal efficiency, FD is considered to contribute to social welfare. Following the seminal work of Oates (1972), the literature has discussed the potential advantages and disadvantages of FD widely; the consensus emerging from this literature is that the effectiveness of FD depends on various related institutional and structural factors (see, for example, Oates, 1999; Tanzi, 2000; De Mello, 2000; Bouton et al., 2008; and Neyapti, 2004, $2006,2010)$. Among the growing number of studies that investigate the effects of FD, those that are of particular interest for the current study focus mainly on the growth implications of FD, and show mixed evidence at that (see, for example, Davoodi and Zou, 1998; Lin and Liu, 2000; Martinez-Vazquez and McNab, 2006; Thiessen, 2003). More recently, a number of studies focus on the welfare implications of FD and emphasize the significance of the various attributes of redistributive mechanisms for effective implementation of FD (see, for example, Sanguinetti and Tomassi, 2004; Stowhase and Traxler, 2005; Akin et al., 2010).

\footnotetext{
We deeply appreciate the financial and academic support provided by the Scientific and Technological Research Council of Turkey (TUBITAK \#109K122). We also thank to the valuable comments of the participants at the 2011 WEAI conference in San Diego.

* Corresponding author. Tel.: (90) 3122902030.

E-mail addresses: neyapti@bilkent.edu.tr (B. Neyapti),zbulut@bilkent.edu.tr (Z.B. Bulut-Cevik).
}

The current paper contributes to this literature by providing a formal analysis of the welfare implications of a fiscal institutional mechanism defined by a redistributive rule, an investment rule, and FD. By doing this, we address three crucial aspects of fiscal institutional design that complement each other and are considered increasingly in the recent policy reform agendas. ${ }^{1}$

In view of the large vertical and horizontal gaps in both less developed and developed countries, ${ }^{2}$ redistribution remains to be a key issue of fiscal policy and redistributive rules are therefore an important aspect of institutional design. ${ }^{3}$ Favorable macroeconomic effects of fiscal rules have recently been discussed by Alesina and Bayoumi (1996) and by the IMF (2009). In a theoretical paper, Sanguinetti and Tomassi (2004) demonstrate that a redistributive rule is preferred to discretion for local governments to attain fiscal efficiency. ${ }^{4}$ In a recent study, Akin et al. (2010; ABCN henceforth) investigate the effectiveness of FD considering a transfer mechanism that both punishes inefficiency in tax collection and compensates for the deviation from target income levels. ${ }^{5}$ The authors show that, under such a redistributive rule, FD increases fiscal efficiency provided

\footnotetext{
${ }^{1}$ Neyapti (2013) provides empirical evidence for the significant impact of fiscal rules on the effectiveness of FD.

2 Although developing countries have greater vertical gaps than developed countries on average, even in developed countries that are federal states, such as Canada, Switzerland, US and Germany, central government transfers constitute $50 \%$ to $70 \%$ of local budgets.

3 Boadway and Shah (2007) provide an extensive account of the issues regarding the design of intergovernmental transfers, stressing the importance of assessing local expenditure needs and revenue capacities.

${ }^{4}$ The authors argue that discretionary redistribution provides insurance against large local shocks, but is not preferable under high degree of FD.

${ }^{5} \mathrm{Ma}$ (1997) points out that among the transfer systems observed in practice, those that take into account both revenue capacities and expenditure needs are the most developed, although also the most demanding, ones.
} 
that budget constraint applies. Neyapti (2013) shows empirically that fiscal rules enhance the fiscal disciplinary effects of FD. These findings are relevant not only for fiscal institutional design in given economy but also for an economic union, for which an exemplary case is the recent economic crises in the EU where fiscal decentralization is not accompanied by well-enforced fiscal rules. ${ }^{6}$

Welfare implications of FD have been investigated in several recent theoretical studies. Lockwood (2002, 2008) employs political economy models to show that the decentralization theorem ${ }^{7}$ fails under fairly unrestrictive conditions. Bataglini et al. (2010) propose a dynamic behavioral model to investigate the extent of the free-riding problem, where the central versus decentralized decision making is analyzed with regard to the investment and consumption choices. The authors conclude that the mechanism characterized by the central government decision on investment and redistribution is superior to the decentralized decision in terms of the steady state levels of investment and the public good. The results are supported by an experimental analysis and shed light on the dynamic aspects of public good provision. Chu and Yang (2012) investigate the growth and welfare implications of $\mathrm{FD}$, vis a vis fiscal centralization (FC, under which externalities are internalized and fiscal activity is coordinated), with a focus on tax competition and tax coordination, and allowing for varying degrees of capital mobility. The authors argue that centralization generates more welfare than FD when public good spillovers are above some threshold level; if not, the degree of capital mobility (tax competition) matters for welfare comparison although FD always dominates FC in regard to growth.

The current paper also uses a dynamic framework, but departs from the foregoing studies in that it investigates the welfare effects of an $\mathrm{ABCN}$-type redistributive rule that takes both efficiency and equity criteria into account. Additionally, it considers that a predetermined part of transfers is centrally directed to local capital accumulation, a feature that conforms to both Battaglini et al.'s findings and Chu and Yang's conjecture in that centralization of some aspects of the fiscal regime enhances the welfare effects of FD. ${ }^{8}$ Given this institutional setup, local governments choose their tax-collection efforts $(A)$ to maximize their lifetime utility. The cost of increasing $A$ is the loss of utility due to reduced local disposable incomes; whereas the gain is the increased transfers, a pre-determined part of which is directed toward capital accumulation. Localities are differentiated by their initial capital. General budget deficits are not allowed since ABCN identifies this as a condition for FD to lead to fiscal efficiency. The issues of tax competition and factor mobility that are commonly investigated in the fiscal federalism literature are ignored in the current model due to a high level of complexity they would add to the model. $^{9}$

We solve the local government's optimization problem for the steady state, subject to the redistribution rule. Given to the complicacy of the comparative statics expressions, we perform simulations across all the feasible ranges of the model's parameters. The analysis reveals several novel findings. First and foremost, the main elements of the redistributive rule proposed here, namely the rate of punishment of fiscal inefficiency and income compensation, are both observed to be effective instruments not only for improving the level of fiscal efficiency, but also for increasing long-term welfare. Second, while centralizing revenues

\footnotetext{
${ }^{6}$ A fiscal union for the EU members has been discussed since the 1970 Werner Report. 7 The theorem, due to Oates (1972) states that decentralizing tax collection and public good provision is welfare-enhancing especially when regions are heterogeneous and the spillovers are small.

${ }^{8}$ Petchey and MacDonald (2007) analyze the effects of conditional grants for capital accumulation in South Africa.

${ }^{9}$ Lack of coordination between the central and local governments under FD is commonly argued to lead to tax competition and underprovision of the public good. Wilson (1999) argues that in case regions fail to internalize their externalities fully, a corrective subsidy system improves efficiency, similar to the role our transfer rule plays in the current model. Chu and Yang (2012) also suggests combining FD with a central coordination device of fiscal authority.
}

increases fiscal efficiency, increasing the tax rate reduces it, as in the falling part of the tax-Laffer curve. ${ }^{10}$ Third, the rate of investment-ended transfers is, interestingly, associated negatively with tax collection effort and transfers. Finally, while income distribution improves with the pervasiveness of the central government (increasing in both centralization and tax rates); welfare decreases with it. These observations indicate that an ideal fiscal institutional design does not necessitate fiscal decentralization to improve either welfare or income distribution, both of which may as well improve with a well designed fiscal rule instead. While stringent and well-enforced fiscal rules increase efficiency, decentralization, increasing taxes and investment-ended transfers may lead to efficiency losses. It should be noted, however, that since this paper refrains from spillover effects across regions due to increased complexity of analysis, some of the findings may be modified in case they are taken into account.

The rest of the paper is organized as follows. Section 2 describes the model. Section 3 discusses the comparative statistics and reports the results of the simulation analysis. Section 4 concludes.

\section{The model}

We consider a representative local government $i(i=1 \ldots n)$ that maximizes its lifetime total utility derived from the spending of the local private $\left(C_{i}\right)$ and government sectors $\left(G_{i}\right)$ by choosing the level of efficiency in tax collection: $A_{i}$ :

$\operatorname{Max}_{A_{i}} \sum_{\mathrm{t}=0}^{\infty} \rho^{t}\left(\alpha \ln \mathrm{C}_{\mathrm{i}, \mathrm{t}}+\beta \ln \mathrm{G}_{\mathrm{i}, \mathrm{t}}\right)$

where $\rho$ is the discount factor, which is assumed to be constant across the $n$ local governments. $\alpha$ and $\beta$ represent the utility weights of the private and government spending that are given by:

$C_{i, t}=\left(1-t_{i}\right) y_{i, t} ;$ where $t_{i}=t . A_{i}$

$G_{i, t}=(1-c) t_{i} y_{i, t}+\gamma T R_{i, t}$

where $y_{i}$ stands for (per capita) income in the $i$ th locality. $t_{i}$ is the effective tax rate for local government $i$; $t$ is the tax rate and $A_{i}$ is the tax collection effort (where $0 \leq A_{i t} \leq 1$ ). Private consumption is equal to the after-tax income, and there are no private savings. $c$ stands for the share of tax revenues accruing to the central government; hence $(1-c)$ represents the degree of fiscal (revenue, to be specific) decentralization, which is assumed to be given exogenously. ${ }^{11}$ Given $t$, which is determined centrally and is assumed to be uniform across localities, Eq. (3) stands for the budget constraint of local government $i$. The term $\gamma$ TR in Eq. (3) implies that $\gamma$ portion of transfers is declared centrally to be used as part of the local governments' current spending. ${ }^{12}$ The remaining transfers, $(1-\gamma) T R$, are invested locally, by the local governments. Hence, the level of investment in region $i$ is given by: $I_{i, t}=(1-\gamma) T R_{i, t}$. Note that total local spending for locality $i\left(C_{i, t}+G_{i, t}+I_{i, t}\right)$ is equal to the portion of after-tax income that remains in the locality: $\left(1-c t_{i}\right) y_{i, t}$, plus the transfers received $\left(T R_{i, t}\right)$. Hence, total local spending is not necessarily

\footnotetext{
10 The finding that centralization is associated with higher efficiency is not surprising in the case of lack of major heterogeneity, which only takes the form of income differentials in the current model.

11 One may consider that both central and local governments collect the revenues from a locality where the shares of each are $c$ and $(1-c)$, which would be equivalent to the current setup with the additional assumption that $A_{i}$ 's are identical under the two regimes. $\mathrm{Al}$ ternatively, Aslim and Neyapti (2013) presents of politico-economic model where $c$ is determined endogenously.

12 This type of transfers, where the end use is pre-determined when transfers are disbursed, is referred to as directed- or closed-ended budget transfers.
} 
equal to local income $\left(y_{i, t}\right)$ because net transfers $\left(T R_{i, t}-c t_{i} y_{i, t}\right)$ can be positive or negative. ${ }^{13}$

A representative local government faces a pre-determined rule that redistributes the central pool of revenues $\left(T R_{t}=\Sigma_{i} c t_{i} y_{i, t}\right)$ by both punishing the inefficiency in tax collection and compensating for the deviation from the target income level $\left(y_{i}^{*}\right)^{14}$ :

$T R_{i, t}=p t y_{i, t}\left(A_{i, t}-1\right)+m\left(y_{i, t}{ }^{*}-y_{i, t}\right)$.

The rate of punishment for inefficiency in tax collection (that is when $\left.\left(1-A_{i}\right)>0\right)$ is $p$, and the rate of compensation of the deviation of income from its target level is $m$. Assuming that there is no lack of information or informational asymmetry across the levels of the government, the first part of Eq. (4) implies that a locality that is not fully effective in tax collections $\left(A_{i}<1\right)$ receives less transfers than is implied by the second part of the expression. The production function is of Cobb-Douglass type (Eq. (5)) and exhibits constant returns to scale, where technology is assumed to be fixed (and normalized to 1). The capital stock follows the usual accumulation rule, where capital accumulation occurs only through investment-ended transfers from central to local governments (Eq. (6)):

$y_{i, t}=k_{i, t}^{\theta}($ where $0<\theta<1)$

$k_{i, t}=(1-\delta) k_{i, t-1}+(1-\gamma) T R_{i, t-1}=(1-\delta) k_{i, t-1}+I_{i, t-1}$

where $\delta$ is the rate of depreciation $(0<\delta<1)$ and $k$ is the per capita level of capital. In brief, local governments maximize (1) subject to (4) and (6), given Eqs. (2), (3) and (5). After substituting Eq. (5) into Eqs. (2) and (3); Eq. (4) into Eqs. (3) and (6), and then Eqs. (2) and (3) into Eq. (1), the local government problem can be written as:

$\operatorname{Max}_{A_{i}} \sum_{\mathrm{t}=0}^{\infty} \rho^{t}\left(\alpha \ln \left[\left(1-\mathrm{t}_{\mathrm{i}}\right) k_{i t}^{\theta}\right]+\beta \ln \left[(1-\mathrm{c}) t_{i} k_{i t}^{\theta}+\gamma p t k_{i t}^{\theta}\left(A_{i t}-1\right)+\gamma m\left(y_{i t}^{*}-k_{i t}^{\theta}\right)\right]\right)$

subject to

$k_{i t}=(1-\delta) k_{i t-1}+(1-\gamma)\left[p t k_{i t}^{\theta}\left(A_{i t}-1\right)+m\left(y_{i t}^{*}-y_{i t}\right)\right]$.

The solution of the above problem yields the following first order condition (see Appendix 1.a):

$\rho^{t}\left[-\frac{\alpha t k_{i t}^{\theta}}{C_{i t}}+\frac{\beta}{G_{i t}}\left((1-c) t k_{i t}^{\theta}+\gamma p t k_{i t}^{\theta}\right)\right]-\lambda_{t}+$
$\rho^{t+1}\left[\begin{array}{l}\frac{\alpha}{C_{i+1}}\left(\theta k_{i t+1}^{\theta-1} \frac{\partial k_{i t+1}}{\partial A_{i t}}-t A_{i t+1} \theta k_{i t+1}^{\theta-1} \frac{\partial k_{i t+1}}{\partial A_{i t}}\right)+ \\ \frac{\beta}{G_{i t+1}}\left((1-c) t A_{i t+1} \theta k_{i t+1}^{\theta-1} \frac{\partial k_{i t+1}}{\partial A_{i t}}+\gamma p t \theta k_{i t+1}^{\theta-1}\left(A_{i t+1}-1\right) \frac{\partial k_{i t+1}}{\partial A_{i t}}-\gamma m \theta k_{i t+1}^{\theta-1} \frac{\partial k_{i t+1}}{\partial A_{i t}}\right)\end{array}\right]=0$

$A_{i t} \leq 1 ; \quad \lambda_{t} \geq 0 ; \quad \lambda_{t}\left(1-A_{i t}\right)=0$

where $\lambda_{t}$ is the value of Lagrange multiplier at time $t$. The second order conditions of the maximization problem are also satisfied (see Appendix 1.b). Based on the complementary slackness condition, there are two cases arising, the first one being $A_{i t}<1$ (and $\lambda_{t}=0$ ) and the other is the full effort case $\left(A_{i t}=1\right)$. We consider the first case to be the interesting one, although the latter case is also reviewed in the Appendix 1.

\footnotetext{
${ }^{13}$ For the aggregate, however, $\sum_{i=1}^{n} T R_{i}=\sum_{i=1}^{n} c t_{i} y_{i}$ for all $t$.

14 as has been formulated originally by $\mathrm{ABCN}$.
}

Defining the steady state by the constant levels of optimal capital and income $\left(\bar{k}\right.$ and $\bar{y}$ ), we obtain the optimal solution of $A_{i}$ (for the case $A_{i t}<1$ ) for the steady-sate using the Matlab program. ${ }^{15}$ The solution involves two distinct roots; accordingly, the steady-state values of the rest of the variables $(k, Y, T R, U)$ are calibrated using each of these roots. Assuming a target rate of -percent annual increase for each local income level $\left(y_{i t}^{*}=(1+\eta) k_{i t}^{\theta}-1\right)$, the steady state levels of income, transfers and utility are given by:

$\overline{T R}=\bar{k}^{\theta}[p t(\bar{A}-1)+\eta m]$

$\bar{y}=\bar{k}^{\theta}$

$\bar{U}=\alpha \ln \left((1-t \bar{A}) \bar{k}^{\theta}\right)+\beta \ln \left([(1-\mathrm{c}) t \bar{A}+\gamma p t(\bar{A}-1)+\eta \gamma m] \bar{k}^{\theta}\right)$.

Using the capital accumulation rule for the steady state: $k_{i, t}=$ $(1-\delta) k_{i, t-1}+(1-\gamma) T R_{i, t-1}$, Eqs. (9) and (10), and the two roots of $\bar{A}$ yield no explicit solution for $\bar{k}$. We therefore resort to the simulation analysis using the admissibility conditions, which bound the values of the redistributive parameters ( $p$ and $m$ ), as well as the degree of revenue decentralization, with the interval between 0 and $1 .{ }^{16}$ We consider that the only source of heterogeneity across the regions is their initial capital stocks.

The dynamics of the model can be summarized as follows. Given the transfer rule (Eq. (4)), the values of $C_{i t}$ and $G_{i t}$ (Eqs. (2) and (3)) are determined based on the optimal choices of $A_{i t}$ and its past value $A_{i, t-1}$; the first being through the contemporaneous tax collection $\left(t_{i}\right)$ and the latter is via the past period's transfers that affect $k_{i, t}-1$, and hence $k_{i, t}$ and $y_{i, t}$ through Eq. (6). The next section reports the findings from the comparative statics of the optimal steady-state solutions of $\bar{A}_{i}, \overline{T R}_{i}$, $\bar{k}_{i}, \bar{y}_{i}$ and $\bar{U}_{i}$.

\section{Simulation results/1mplications}

In this section, we examine the effects of the main parameters of the proposed transfer mechanism: $p, m$ and $\gamma$; the rest of the fiscal parameters: $c$ and $t$; and the structural parameter $\theta$, on the steady-state levels of tax collection effort, ${ }^{17}$ transfers and utility. Because the partial derivatives of the steady-state expressions (given in the previous section) with respect to the underlying model parameters are highly nonlinear and do not yield explicit solutions, comparative statics are obtained via simulation analysis. Table 1 reports the parameter values that are used to simulate the model. The utility shares of the private and public spending: $\alpha$ and $\beta$ respectively, are approximated by the relative sizes of private and public sectors, the world average for the latter or which being $30 \%{ }^{18}$ The rates of depreciation, $\delta,{ }^{19}$ and discount, $\rho$, follow the standard literature.

As Table 1 shows, simulations exhaust all the possible ranges of the model-specific parameter values, called admissibility constraints. The differential initial capital levels are the source of heterogeneity across the local governments so as to ensure that some redistribution is realized. For tractability, the analysis is conducted for two localities, for which the initial levels of (per capita) capital are taken as 1 and 4,

\footnotetext{
15 The solution code is too long to report here, but is available from the author upon request.

${ }^{16}$ We use the fsolve function in Matlab that yields approximate solutions for $\bar{k}$.

17 Because the second root of $\bar{A}$ yields no solution for the comparative statics, we use the first root in the rest of the simulation analysis.

18 based on International Financial Statistics database of the World Bank.

19 Nadiri and Prucha (1996) shows that the depreciation rate for physical capital is 0.06 and for R\&D is 0.12 for the US manufacturing sector.
} 
Table 1

Parameters of the model.

\begin{tabular}{lll}
\multicolumn{2}{l}{ Structural parameters: } \\
$\delta$ & 0.1 & Depreciation rate \\
$\rho$ & 0.95 & Discount factor \\
$\alpha$ & 0.7 & Utility share of private consumption \\
$\beta$ & 0.3 & Utility share of public consumption \\
$\eta$ & 0.1 & Targeted increase in local income \\
Admissibility constraints: & \\
$m$ & {$[0,1]$} & Income compensation parameter \\
$p$ & {$[0,1]$} & Punishment rate for inefficiency in tax collection \\
$\gamma$ & {$[0,1]$} & The rate investment-ended transfers \\
$\mathrm{c}$ & {$[0,1]$} & Degree of revenue decentralization \\
$t$ & {$[0,1]$} & Tax rate \\
$\theta$ & {$[0,0.5]$} & Income share of capital \\
\hline
\end{tabular}

a Mankiw et al. (1992) show that $\theta=1 / 3$ for the case of the US, which is within the broad range assumed here.

indicating that the second region is more capital-intensive than the first. The following general government budget constraint applies:

$T R_{t}=\left(T R_{1, t}+T R_{2, t}\right) \leq c t\left(A\left(y_{1, t}+y_{2, t}\right)\right)$

which states that total transfers cannot exceed total tax revenues of the central government; hence an individual locality may receive positive or negative transfers. The left side of the inequality also satisfies Eq. (4).

Simulations of the steady state solutions yield in 6285 data points that meet the admissibility constraints..$^{20}$ Based on these data, the responses of the optimal steady state values $\left\{\bar{A}_{i} ; \overline{T R}_{i} ; \bar{k}_{i} ; \bar{y}_{i} ; \bar{U}_{i}\right\}$ to the fiscal parameters $\{p, m, \gamma, c, t\}$ are analyzed and are reported in the following table:

A crucial finding reported in Table 2 is that increasing both the punishment rate, $p$, and the income compensation rate, $m$, increases the steady-state level of fiscal effort, or the tax collection efficiency, unambiguously. This observation supports the efficiency enhancing effect of the suggested redistributive rule. The positive effect of $p$ is as expected, and that of $m$ appears counterintuitive at first but can be explained as follows. When the income compensation rate is high, the steady-state level of transfers is also high, which gives incentive to the local governments to increase their effort to get a larger share of the increasing pool. This can be interpreted as the substitution effect of the incomecompensation parameter.

Result 1. The parameters of the suggested redistribution rule all have an unambiguous positive effect on fiscal efficiency: $(\partial \bar{A} / \partial p>0 ; \partial \bar{A} / \partial m>0$; and $\partial \bar{A} / \partial(1-\gamma)>0$ ) (see Appendix 2).

The positive effects of the redistributive parameters on efficiency (total effort of the two regions) are diminishing in the respective parameters, although they increase in the degree of centralization, $c$. This points at the significant role of fiscal rules in alleviating the public good problem; in the presence of a fiscal rule, increased common pool of revenues incentivize local governments to increase their efficiency in order to obtain a greater share of that common pool. By contrast, the efficiency effects of the fiscal rule parameters decrease with the tax rate as the local governments try to counterbalance the negative effect of increasing the tax rate on local disposable incomes and thus utility derived from private consumption.

Remark 1. The more centralized the fiscal revenues, the more effective is the proposed fiscal rule in increasing fiscal efficiency.

Besides its indirect (second order) effects on fiscal efficiency, the tax rate also has a direct negative effect on the tax collection effort, for the reason just explained. This negative relationship increases in $c$, but decreases in $t$; the reason for the first is that as the centralized pool of

\footnotetext{
20 The number increases with the reduced intervals chosen for the parameter values in the simulation. Admissibility criteria consist, in addition to the parameter constraints listed in Table 1, of the non-negativity of capital, consumption and government spending, in addition to $(0,1)$ bound for the tax collection effort.
}

Table 2

Comparative statics: (for $0 \leq p, m, \gamma, c, t \leq 1$ and $0.1 \leq \theta \leq 0.5$ ).

\begin{tabular}{llllll}
\hline & $p$ & $m$ & $(1-\gamma)^{\mathrm{a}}$ & $c$ & $t$ \\
\hline $\bar{A}$ & + & + & - & + & - \\
$\bar{U}$ & + & + & na & - & - \\
$\overline{T R}$ & - & + & - & na & na \\
\hline
\end{tabular}

Note: "na" indicates ambiguity in the relationship.

a The portion of transfers earmarked for local investment spending.

revenues increases, ceteris paribus, reducing fiscal effort compensates for the negative effect of increasing taxes on local incomes without reducing the level of transfers that may now be received in through income compensation given the hard budget constraint (Eq. (12)). The observation of the diminishing negative effect of the tax rate on tax collection effort points at the decreasing role of income compensation in overcoming the increase in the disutility from punishment due to the reduction in the effort in tax collection; tax effort therefore falls at a decreasing rate as the tax rate rises.

Result 2. The negative effect of taxes on fiscal efficiency increases with the centralization of revenues but decreases in the tax rate. (see Appendix 3).

The rate at which transfers are earmarked for investment $(1-\gamma)$ has a negative effect on both tax collection effort and transfers. ${ }^{21}$ While the reason for this may not be obvious, it reflects the long-term positive effect of increasing investment, ceteris paribus, on income (remember that investment ended transfers is the only way for capital accumulation), which in turn allows for lower steady-state effort to attain the same level of utility, which can be viewed as the wealth effect. ${ }^{22}$ Since local governments receive utility both from their own (current and investment) spending and from the private sector spending, an increase in the longterm capital stock and thus disposable income of the private sector, local governments can afford to exert lower tax effort to attain the same level of utility as before. The same argument can be used to explain the negative effect of the initial capital level on the steady-state level of tax effort.

Result 3. Investment-ended transfers are associated with long-term efficiency in tax collection (see Appendix 4).

A testable implication arising from the above results is that fiscal rules are likely to be more effective in countries that centralize fiscal revenues. ${ }^{23}$ Given a level of decentralization and fiscal rule, increasing the rates of tax and investment-ended transfers, however, may not contribute to efficiency.

Another important implication of the redistributive mechanism studied is in regard to income distribution (measured here as $Y_{1} / Y_{2}$ ). Fairness in income distribution increases in the punishment rate; with regard to the rate pervasiveness (rates of taxes and their centralization), however, the relationship is negative. ${ }^{24}$ Similarly, welfare (sum of regional utilities) decreases in the pervasiveness of the central government. In addition, income distribution is observed to worsen in $\theta$. This is because the volume of transfers arising from punishment also increases in $\theta$, which is the moral hazard effect of increased income. It is worth noting that

\footnotetext{
21 This result may not hold when a consumer optimization problem is added to the current framework, which is beyond the scope of the current paper however.

22 The generality of this result, however, may be questioned on the grounds that the current model assumes away heterogeneity in preferences.

${ }^{23}$ Neyapti (2013) shows that the effectiveness of FD increases with fiscal rules. As better fiscal rules (FR) may be implemented in more decentralized countries, the findings of this paper suggest that the same quality of FR may perform better the more centralized is the fiscal policy,

24 The finding that decentralization leads to greater equality than the case of centralization (compare Block 1 to Column 3) is inconsistent with the finding of ABCN (2011); using the same transfer rule in a static set-up, $A B C N$ shows that centralization leads to higher equality whereas decentralization leads to greater efficiency than the other. The difference in the findings points at the importance of taking the long-term perspective in designing institutions to achieve fiscal efficiency.
} 
when $\theta$ is less than or equal to 0.3 (the US figure) the admissible optimal steady state values of the model variables are associated with the rate of punishment of only 1 .

Remark 2. The less pervasive the central government, the greater the welfare and the distributional effects of the proposed redistributive rule (see Appendix 5).

Remark 3. Under the proposed redistributive rule, conditions for improving welfare and income distribution are the same, whereas they are opposite of those for efficiency: increasing tax rate reduces both fiscal efficiency and welfare and worsens income distribution. FD, on the other hand reduces efficiency but improves welfare and income distribution.

Simulations also reveal that transfers fall in the degree at which transfers are directed to investments $(1-\gamma)$. Transfers also decrease in $p$ but increase in $m$, as consistent with the redistributive rule (Eq. (4)).

\subsection{Some policy exercises}

Table 3 reports the simulated values of the aggregate (summed across the regions) tax-collection effort; income and welfare corresponding to some benchmark parameter values. To get a better sense of these parameters one can note that the average tax rate is at most 0.5 or 0.6 in the most developed countries, and much less in developing countries (such as 0.2 in Mexico). The rate of revenue decentralization in even the most decentralized developed countries, say in Switzerland, is less than $0.5 .^{25}$ Hence, a pervasive central government amounts to either highly centralized revenue collection, with or without a high average tax rate, or high average tax rate plus reasonably high revenue decentralization. In that regard, Denmark's (where $c=0.3, t=0.5$ ) central government is not pervasive, whereas China's is (where $c=0.95$ ).

In Table 3, the calibration results for $A, Y$ and $U$ are the sum over the two regions. Hence, one can interpret the Table as the following. Line $i$, representing relatively low $c$ and $t$ values, may stand for a country like Mexico in case it applies a full measure of the proposed redistributive rule (where $p=m=1$ ). This can be contrasted with lines $i i$ and $v$, where income compensation is much less in cases of low (ii) and high (iv) income shares of capital. Of these, highest effort obtains in the first, and lowest welfare in the last case. Line vi may be viewed to stand for the case of China (with high revenue centralization but low tax rates), if China adopted high punishment rate but low income compensation. This case, which only differs in $c$ when compared to the line above, yields higher steady-state effort as well as higher welfare.

Comparing lines $i$ and vi (or lines vii and viii) reveals that increasing centralization, ceteris paribus, increases fiscal efficiency but not welfare. Comparing lines ii to $i v$ shows the effect of increasing the tax rate, which is negative on both efficiency and welfare. Finally, comparing lines ii and iii shows that decreasing the portion investment-earmarked transfers (increasing $\gamma$ ) leads to higher tax effort. These observations are all in lines with the general results reported earlier.

The foregoing observations enable important policy recommendations regarding fiscal institutional design: the proposed transfer rule yields higher welfare under decentralization than centralization, although it yields higher fiscal efficiency under a centralized system than under decentralization.

\section{Concluding remarks}

This paper presents a dynamic model to explore the efficiency of a redistributive rule that punishes the lack of tax collection efficiency of

\footnotetext{
25 Author's calculation based on the OECD at a Glance, 2011, statistics on fiscal revenues by levels of government. The figure is obtained by dividing the sum of the state and local government revenues to the overall government revenues (general, local, state and social security).
}

Table 3

A sample of steady states.

\begin{tabular}{llllllllll}
\hline & $p$ & $m$ & $c$ & $t$ & $\gamma$ & $\theta$ & $A$ & $Y$ & $U$ \\
\hline$i$ & 1 & 1 & 0.3 & 0.3 & 0.5 & 0.1 & 1.47 & 0.2256 & -5.80 \\
ii & 1 & 0.1 & 0.3 & 0.3 & 0.5 & 0.1 & 0.90 & 0.2256 & -7.03 \\
iii & 1 & 0.1 & 0.3 & 0.3 & 0.7 & 0.1 & 1.08 & 0.2256 & -6.87 \\
iv & 1 & 0.1 & 0.3 & 0.7 & 0.5 & 0.1 & 0.86 & 0.2256 & -7.33 \\
v & 1 & 0.1 & 0.3 & 0.3 & 0.5 & 0.3 & 0.90 & 0.0029 & -15.77 \\
vi & 1 & 0.1 & 0.9 & 0.3 & 0.5 & 0.1 & 1.79 & 0.2256 & -7.27 \\
vii & 1 & 0.2 & 0.3 & 0.5 & 0.9 & 0.3 & 1.23 & 0.0029 & -15.31 \\
viii & 1 & 0.2 & 0.9 & 0.5 & 0.9 & 0.3 & 1.97 & 0.0029 & -15.74 \\
ix & 0.1 & 0.1 & 0.3 & 0.3 & 0.3 & 0.5 & 0.14 & 0.0000 & -24.64
\end{tabular}

local governments and compensates for the deviation of local incomes from a target level. The redistributive rule is coupled by a policy of directed transfers that allocates an exogenously specified (by the central government) portion of the transfers (determined according to the aforementioned rule) to local capital accumulation.

The findings based on the comparative statics of the model's solution for the steady state reveal that both punishment of fiscal inefficiency and compensation of regional income deficiency are essential for increasing fiscal discipline and welfare. However, while centralization of revenues improves fiscal efficiency, it deteriorates both welfare and income distribution. Given the proposed redistributive rule, increasing the tax rate and investment-ended transfers, especially in cases of highly centralized revenues, do not contribute positively to efficiency or welfare. The findings shed light to the contradiction between the original arguments of the decentralization literature and the recent literature that formally demonstrates the failure of the decentralization theorem, by demonstrating the role of the fiscal rules for welfare implications of fiscal decentralization.

The findings bear interesting implications for fiscal discipline in economic unions as well as in a single economy with large vertical and horizontal imbalances that necessitate an effective transfer mechanism. In the case of the European Union, for example, where, akin to different local decision making units of a fiscally decentralized country, the union faces a single central bank but independent fiscal authorities, the importance of imposing a fiscal rule for redistribution across the states has become even more evident with the recent crises. As future potential research areas, the observations based of the proposed model can be tested empirically. Further extensions could involve modifications of the current framework to incorporate the political economy aspects, such as modeling the game between the central and the local governments, and the optimal choice of FD given the degrees of political fragmentation and spillover effects, which are among the ongoing projects of the authors of the current study.

\section{Appendix 1. Optimality checks}

\section{A1. First order analysis}

The constraint qualification is obviously satisfied since the constraints are linear. Also note that objective function is concave. So we can apply Kuhn Tucker's theorem. The Lagrangean expression is obtained after substituting Eq. (4) into Eq. (3) and substituting Eqs. (2) and (3) into Eq. (1):

$$
\begin{aligned}
L= & \sum_{\mathrm{t}=1}^{\infty}\left(\alpha \ln \left(\mathrm{y}_{\mathrm{i}, \mathrm{t}}-\mathrm{t} A_{i, t} \mathrm{y}_{\mathrm{i}, \mathrm{t}}\right)+\beta \ln \left((1-\mathrm{c}) \mathrm{t} A_{i, t} \mathrm{y}_{\mathrm{i}, \mathrm{t}}+\gamma\left(\mathrm{pty}_{\mathrm{i}, \mathrm{t}}\left(A_{i, t}-1\right)\right.\right.\right. \\
& \left.\left.\left.+m\left(y_{i, t}^{*}-y_{i, t}\right)\right)\right)+\lambda_{\mathrm{t}}\left(1-\mathrm{A}_{\mathrm{i}, \mathrm{t}}\right)\right) .
\end{aligned}
$$


Maximizing this expression yields the following first order conditions:with respect to $A_{i, t}$ :

$\rho^{t}\left(-\frac{\alpha t k_{i t}^{\theta}}{C_{i t}}+\frac{\beta}{G_{i t}}\left((1-c) t k_{i t}^{\theta}+\gamma p t k_{i t}^{\theta}\right)\right)-\lambda_{t}+$

$\rho^{t+1}\left[\begin{array}{l}\frac{\alpha}{C_{i+1}}\left(\theta k_{i t+1}^{\theta-1} \frac{\partial k_{i t+1}}{\partial A_{i t}}-t A_{i t+1} \theta k_{i t+1}^{\theta-1} \frac{\partial k_{i t+1}}{\partial A_{i t}}\right)+ \\ \frac{\beta}{G_{i t+1}}\left((1-c) t A_{i t+1} \theta k_{i t+1}^{\theta-1} \frac{\partial k_{i t+1}}{\partial A_{i t}}+\gamma p t \theta k_{i t+1}^{\theta-1}\left(A_{i t+1}-1\right) \frac{\partial k_{i t+1}}{\partial A_{i t}}-\gamma m \theta k_{i t+1}^{\theta-1} \frac{\partial k_{i t+1}}{\partial A_{i t}}\right)\end{array}\right]=0$

with respect to $\lambda_{t}: A_{i, t} \leq 1, \lambda_{t} \geq 0, \lambda_{t}\left(1-A_{i, t}\right)=0$.

Since $k_{i, t+1}=(1-\delta) k_{i, t}+(1-\gamma) T R_{i, t}=(1-\delta) k_{i, t}+(1-\gamma)\left(p t Y_{i,}\right.$ $\left.{ }_{t}\left(A_{i, t}-1\right)+m\left(Y_{i, t}^{*}-Y_{i, t}\right)\right)$, we get:

$\frac{\partial k_{i t+1}}{\partial A_{i t}}=(1-\gamma) p t k_{i, t}^{\theta}$.

Case 1. If $\lambda_{t}=0$, then $A_{i, t}<1$ (given the constraint $A_{i, t} \leq 1$ in Eq. (8)) Substituting (2), (3), (4) and Eq. (17) into the above Lagrangean function yields the optimum level of $A_{i}$, an explicit solution of which cannot be reached, however. Instead, Matlab is used to obtain symbolic solutions. ${ }^{26}$

For capital, which is a function of $A_{i}$, no explicit solution can be obtained either. We employ the fsolve function in Matlab, as a nonlinear approximation for evaluating the steady state values of $k .{ }^{27}$ Using the simulated values obtained via this solution method, the steady state values of transfers, income and utility are also obtained.

Case 2. Taking $\lambda_{t}>0$ implies that $A_{i, t}=1$, based on which Eq. (4) becomes:

$T R_{i, t}=m\left((1+\eta) k_{i, t-1}^{\theta}-k_{i, t}^{\theta}\right)$.

At the steady state, $\bar{A}=1$; and $\bar{k}=\left(\eta \frac{1-\gamma}{\delta} m\right)^{\frac{1}{1-\theta}}$.

In the full effort case, steady state capital decreases in $\gamma, \delta$, and $\theta$ (because the term in parentheses is less than one) and increases in $m$ unambiguously. However, it is not plausible to take Case 2 as optimal in any given period due to the incentives local governments usually face to spend less than full tax collection effort.

\section{A2. Second order analysis}

Because the constraint qualification and first order condition are satisfied, then, in a generic form:

$D^{2} L(\bar{x}, \bar{\lambda})=D^{2} f(\bar{x})+\sum_{i=1}^{j} \bar{\lambda}_{i} D^{2} g_{i}(\bar{x})$

where $\bar{x}$ is taken as the optimal choice variable, $f$ is the objective function and $j$ is the number of constraints.

Since the model's inequality constraint is linear, its second order derivative is zero, that is, the second part of the above equation disappears. So,

$D^{2} L(\bar{A}, \bar{\lambda})=\left[\frac{\alpha t k_{i t}^{\theta}}{C_{i t}{ }^{2}}\left(-t k_{i t}^{\theta}\right)-\frac{\beta}{G_{i t}{ }^{2}}\left((1-c) t k_{i t}^{\theta}+\gamma p t k_{i t}^{\theta}\right)^{2}\right]+$

$\rho\left[\begin{array}{l}-\frac{\alpha}{C_{i+1}^{2}}\left(\theta k_{i t+1}^{\theta-1} \frac{\partial k_{i t+1}}{\partial A_{i t}}-t A_{i t+1} \theta k_{i t+1}^{\theta-1} \frac{\partial k_{i t+1}}{\partial A_{i t}}\right)^{2}- \\ \frac{\beta}{G_{i t+1}^{2}}\left((1-c) t A_{i t+1} \theta k_{i t+1}^{\theta-1} \frac{\partial k_{i t+1}}{\partial A_{i t}}+\gamma p t \theta k_{i t+1}^{\theta-1}\left(A_{i t+1}-1\right) \frac{\partial k_{i t+1}}{\partial A_{i t}}-\gamma m \theta k_{i t+1}^{\theta-1} \frac{\partial k_{i t+1}}{\partial A_{i t}}\right)^{2}\end{array}\right]$.

Since $\frac{\partial^{2} k_{i t+1}}{\partial^{2} A_{i t}}=0, \alpha>0, \beta>0$ and the other terms are in square forms then $D^{2} L(\bar{A}, \bar{\lambda})<0$. Hence, the second order condition is satisfied unconditionally.

\footnotetext{
26 The above Lagrangean equation is nonlinear; MATLAB solves for a nonlinear function if there is a symbolic solution. For this specific problem, the solution for the optimal tax effort exists, which is too long to report here (available upon request).

27 The capital accumulation rule yields the steady state value of capital; but since no explicit can be obtained, it is calculated numerically.
}

\section{Appendix 2. Comparative statics}
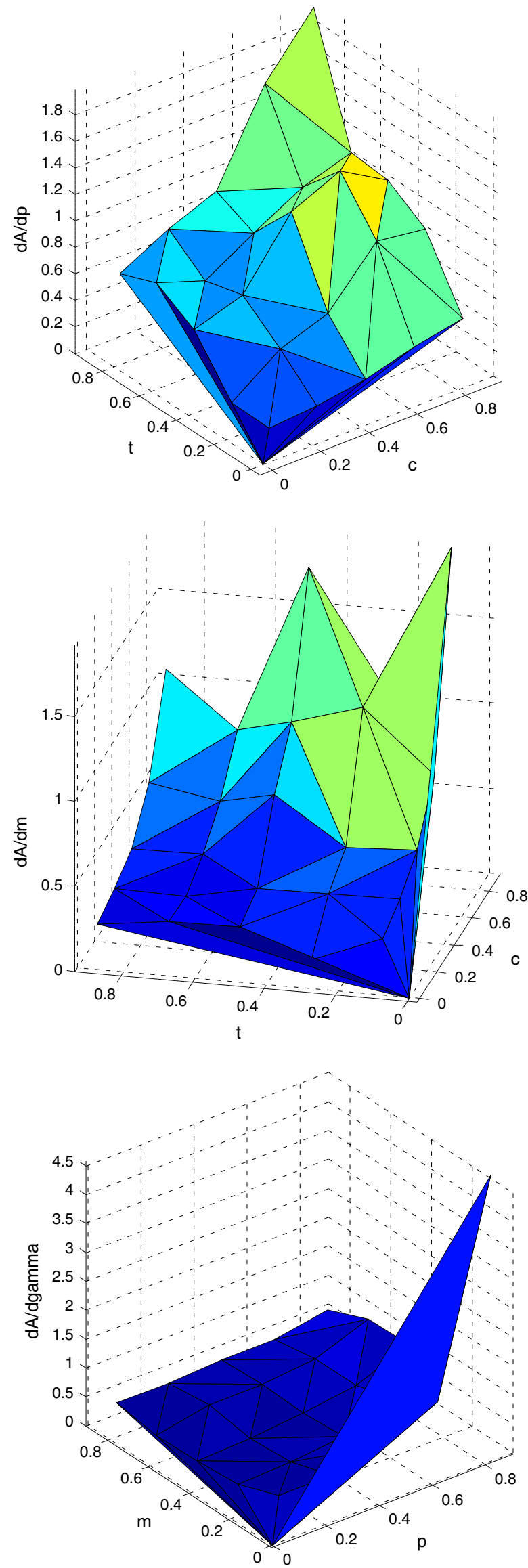
Appendix 3. Pervasiveness and the response of tax effort to the tax rate

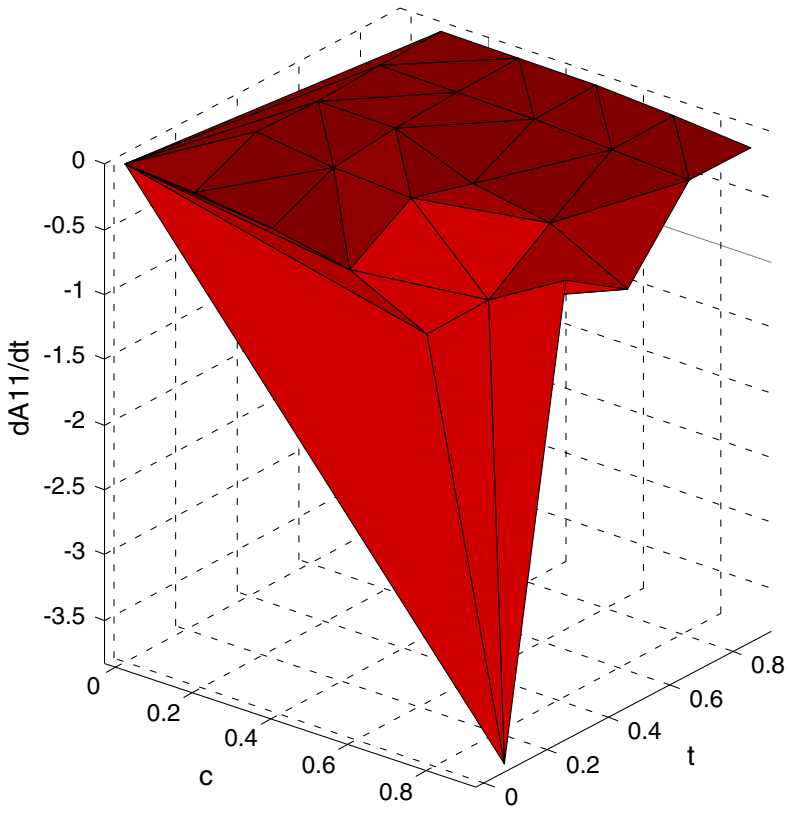

Appendix 4. Investment-ended transfers $(1-\gamma)$ (the vertical axis should be read as negative)
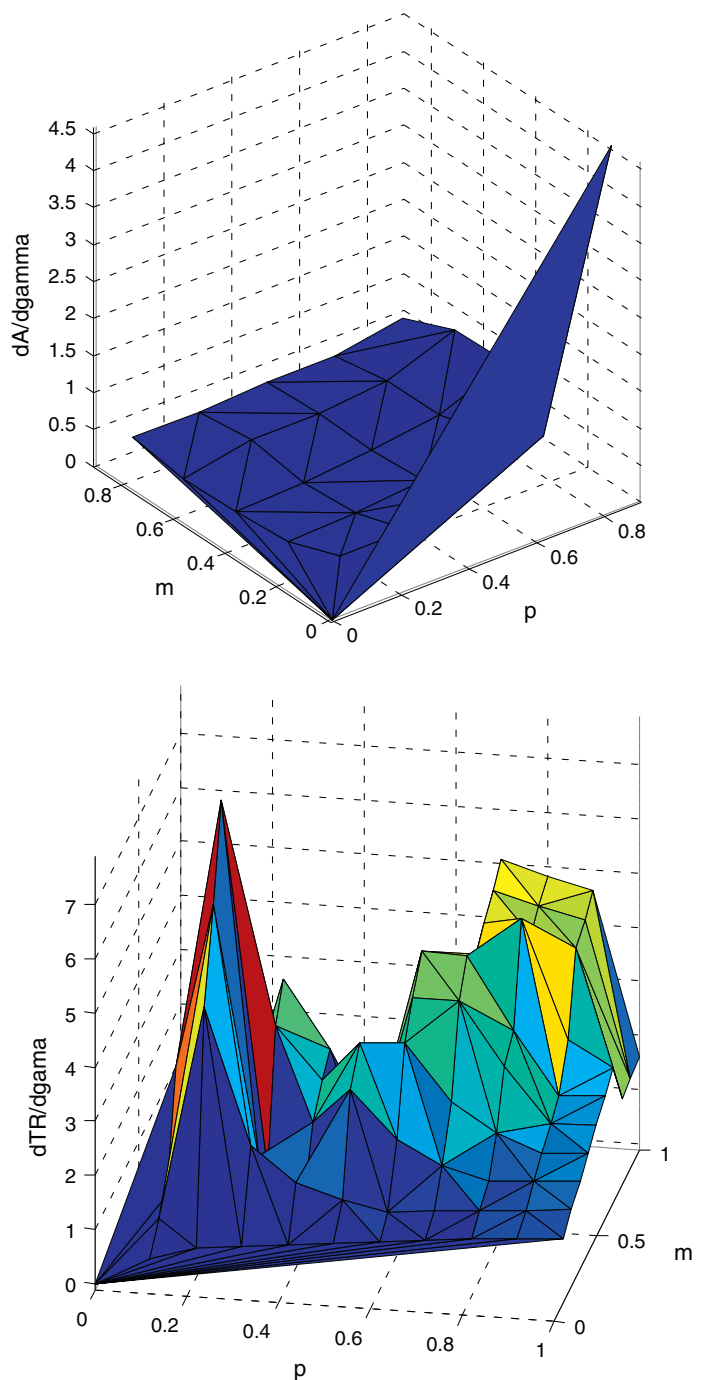

Appendix 5. Income distribution, welfare and state pervasiveness
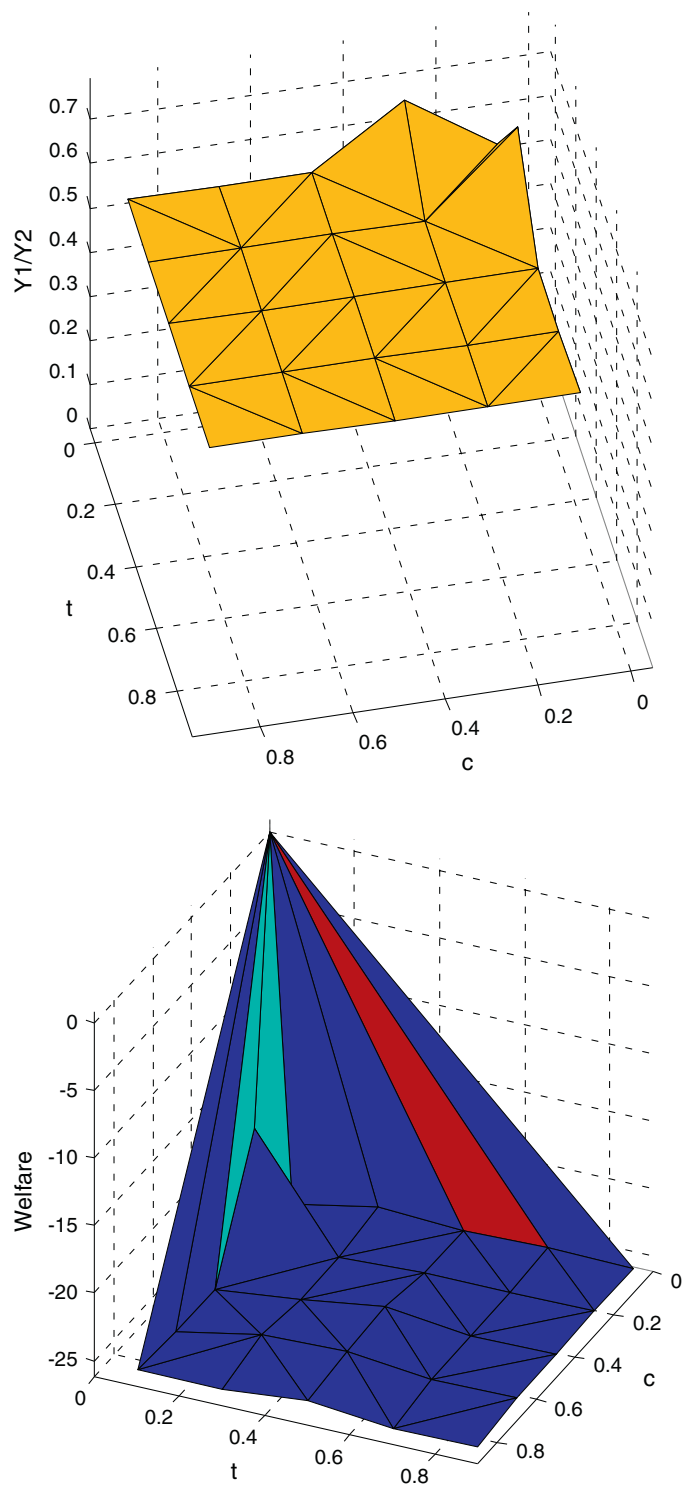

\section{References}

Akin, Z., Bulut-Cevik, Z.B., Neyapti, B., 2010. Does Fiscal Decentralization Promote Fiscal Discipline? Bilkent University Discussion Paper 11-01.

Alesina, A., Bayoumi, T., 1996. The Costs and Benefits of Fiscal Rules: Evidence From U.S. States. NBER, Working Paper, No. 5614.

Aslim, G. and B. Neyapti, 2013. "Welfare Effects of Fiscal Decentralization: a Political Economy Approach", manuscript, Bilkent University.

Bataglini, M., Nunnari, S., Palfrey, T.R., 2010. Political Institutions and the Dynamics of Public Investment. California Institute of Technology, Social Science Working Paper 1318.

Boadway, R., Shah, A., 2007. Intergovernmental Fiscal Relations: Principles and Practice. The World Bank.

Bouton, L., Gassner, M., Verardi, V., 2008. Redistributing income under fiscal vertical ımbalance. Eur. J. Polit. Econ. 24, 7-328.

Chu, A., Yang, C.C., 2012. Fiscal centralization versus decentralization: growth and welfare effects of spillovers, leviathan, and capital mobility. J. Urban Econ. 71, 177-188.

Davoodi, H., Zou, H., 1998. Fiscal decentralization and economic growth: a cross-country study. J. Urban Econ. 43, 244-257.

De Mello, L., 2000. Can fiscal Decentralization Strengthen Social Capital? IMF Working Paper. No. 00/129. International Monetary Fund, Washington D.C.

International Monetary Fund (IMF), 2009. Fiscal Rules-Anchoring Expectations for Sustainable Public Finances. Fiscal Affairs Dept.

Lin, Y.J., Liu, Z., 2000. Fiscal decentralization and economic growth in China. Econ. Dev. Cult. Chang. 49, 1.

Lockwood, R., 2002. Distributive politics and the costs of centralization. Rev. Econ. Stud. 69, 313-337. 
Lockwood, R., 2008. Voting, lobbying and the decentralization theorem. Econ. Polit. 20, 416-431.

Ma, Jun, 1997. Intergovernmental Fiscal Transfer: A Comparison of Nine Countries. World Bank Economic Development Institute, Working Paper Series No. 1822. The World Bank, Washington DC.

Mankiw, N.G., Romer, D., Weil, D.N., 1992. A contribution to the empirics of economic growth. Q. J. Econ. 107, 407-437.

Martinez-Vazquez, J., McNab, R.M., 2006. Fiscal decentralization, macro stability and growth. Rev. Econ. Pública 179, 25-49.

Nadiri, M.I., Prucha, I.R., 1996. Estimation of the depreciation rate of physical and R\&D capital in the U.S. total manufacturing sector. Econ. Inq. 34, 43-56.

Neyapti, B., 2004. Fiscal decentralization, central bank independence and inflation: a panel investigation. Econ. Lett. 82, 227-230.

Neyapti, B., 2006. Revenue decentralization and income distribution. Econ. Lett. 92, 409-416.

Neyapti, B., 2010. Fiscal decentralization and deficits: international evidence. Eur. J. Polit. Econ. 26, 155-166.
Neyapti, B., 2013. Fiscal decentralization, fiscal rules and fiscal discipline. Econ. Lett. 121, $528-532$.

Oates, W., 1972. Fiscal Decentralization. Harcourt Brace Jovanowich, New York.

Oates, W., 1999. An essay on fiscal federalism. J. Econ. Lit. 37, 1120-1149.

Petchey, J., MacDonald, G., 2007. Financing Capital Expenditures through Grants. In: Boadway, Shah (Eds.), Intergovernmental Fiscal Transfers: Principles and Practice. The World Bank, Washington D.C.

Sanguinetti, P., Tomassi, M., 2004. Intergovernmental transfers and fiscal behavior insurance versus aggregate discipline. J. Int. Econ. 62, 149-170.

Stowhase, S., Traxler, C., 2005. Tax evasion and auditing in a federal economy. Int. Tax Public Financ. 12, 515-531.

Tanzi, V., 2000. On Fiscal Federalism: İssues to Worry About. Conference Notes. Conference on Fiscal Decentralization. IMF, Fiscal Affairs Department, Washington D.C.

Thiessen, U., 2003. Fiscal Decentralization and Growth in High-mcome OECD Countries. Fisc. Stud. 24, 237-274.

Wilson, J.D., 1999. Theories of tax competition. Nat. Tax J. 52 (2), 269-304. 